\title{
The Role and Mechanisms of Action of Glucocorticoid Involvement in Memory Storage
}

\author{
Carmen Sandi ${ }^{\dagger}$ \\ Department of Psychobiology, Universidad Nacional de Educacion a Distancia, \\ Ciudad Universitaria s/n, 28040 Madrid, Spain
}

\section{SUMMARY}

Adrenal steroid hormones modulate learning and memory processes by interacting with specific glucocorticoid receptors at different brain areas. In this article, certain components of the physiological response to stress elicited by learning situations are proposed to form an integral aspect of the neurobiological mechanism underlying memory formation. By reviewing the work carried out in different learning models in chicks (passive avoidance learning) and rats (spatial orientation in the Morris water maze and contextual fear conditioning), a role for brain corticosterone action through the glucocorticoid receptor type on the mechanisms of memory consolidation is hypothesized. Evidence is also presented to relate post-training corticosterone levels to the strength of memory storage. Finally, the possible molecular mechanisms that might mediate the influences of glucocorticoids in synaptic plasticity subserving long-term memory formation are considered, mainly by focusing on studies implicating a steroid action through (i) glutamatergic transmission and (ii) cell adhesion molecules.

\section{KEYWORDS}

corticosterone, steroids, glutamatergic transmission, cell adhesion molecules, glucocorticoid receptors

'Dr. Carmen Sandi

Fax: +34-91-398-62-87;

e-mail: csandi@cu.uned.es

\section{INTRODUCTION}

Most current animal models of learning and memory involve an important stress component. A great number of the tasks that are used are either aversively motivated (including a variety of aversive stimulation, such as electric shocks, distasteful flavors, water immersion, and so on) or include experimental manipulations that challenge the homeostasis of the organism (for example, food access restriction in food-motivated learning tasks). Such situations activate, during the training procedure, the physiological stress response. Moreover, even if the task has been designed to minimize stressful factors, the removal of the animals from their home cages and the novelty that is associated with the learning situation can trigger the activation of stress-related systems. For years, neuroscientists working in the field of learning and memory emphasized that research focusing on the understanding of how the nervous system stores information should exclude any factor involving neural influences resulting from stress. We propose that certain components of the physiological response to stress form an integral aspect of the neurobiological mechanisms underlying memory formation.

\section{GLUCOCORTICOIDS: RECEPTORS AND MECHANISMS OF ACTION}

In a number of vertebrate species (including mammals and birds), the response to stress involves both central nervous system and peripheral elements, including the activation of the autonomic nervous system and the hypothalamic-pituitaryadrenocortical (HPA) axis. Glucocorticoids 
(corticosterone being the naturally occurring glucocorticoid in certain species, such as rats and chicks, and cortisol in humans), are the final products of the HPA axis and are released by the adrenal glands. In addition to providing a restraining feedback on the activity of the axis, glucocorticoids regulate a wide number of peripheral responses, including metabolic and immune processes. Given their lipophilic properties, glucocorticoids can easily cross the blood-brain barrier and enter the brain, where they can influence brain function and behavior through binding to different receptor types. Classic glucocorticoid actions are mediated through two distinct receptor types: Type I or mineralocorticoid receptor (MR) and Type II or glucocorticoid receptor (GR). These intracellular receptors are activated by the binding of the glucocorticoid hormone or agonist, which first induces a conformational change in the receptor, leading to the dissociation from its attached heatshock protein (HSP90) (Baulieu, 1987), followed by the activation of nuclear translocation signals and dimerization of activated receptor complexes. Subsequently, the receptor dimer binds to specific nuclear DNA sequences called corticosteroid responsive elements, modulating (either facilitating or suppressing) gene transcription and, therefore, the synthesis of certain proteins (Burnstein \& Cidlowsky, 1989; Dokas et al., 1994; Joëls \& de Kloet, 1994).

Intracellular corticosteroid receptors are differentially distributed throughout the brain; both types are expressed in neurons and in glial cells (Joëls \& de Kloet, 1994). Most localization studies have been carried out in rats. MRs have been shown to display regional heterogeneity in expression, which is mainly confined to limbic areas. MRs are found primarily in the hippocampus, septum, amygdala, layer II of the cortex, cerebellum, and in a number of brain-stem sensory and motor neurons. GRs are expressed more widely in most brain regions, with the highest densities expressed in the hippocampus, the septum, the paraventricular hypothalamic nucleus, and most brainstem mono-aminergic nuclei, with moderately high levels in the striatum, central amygdaloid nucleus, and the cerebral cortex. Corticosterone binding, showing approximately 10 fold greater affinity to MRs than to GRs, along with plasma concentration, determines the in vivo receptor occupancy. Thus, during periods of low, basal circulating corticosterone concentration, MR occupancy in the hippocampus is greater than $70 \%$, whereas GR occupancy is only around $10 \%$. During periods of high corticosterone levels (during stress or at the peak of the circadian variations), however, the occupancy of each receptor can be raised to around $90 \%$.

In addition to genomic action, steroid hormones can influence neural function by interacting with the neuronal membrane (Shumacher, 1990; Orchinik et al., 1991). Different mechanisms of action have been proposed for such effects, including the interaction of steroid metabolites with receptors for other neurotransmitter systems, notably for the $\gamma$-aminobutyric acid $\left(\mathrm{GABA}_{\mathrm{A}}\right)$ receptor, and the binding to putative membrane steroid receptors (Puia et al., 1990). A glucocorticoid membrane site has been well characterized in the amphibian brain (Orchinik et al., 1991). In mammals, rapid behavioral effects of corticosterone have been described that suggest a membrane action of the hormone (Sandi et al,. 1996a,b). In these studies, corticosterone was found to rapidly increase (within $7.5 \mathrm{~min}$ ) the exploration of a novel environment, which could be a potential mechanism by which this steroid influences learning processes. Understanding the mechanisms involved in the fast behavioral effects of corticosterone might be supported by recent studies showing the ability of corticosterone to produce rapid increases in the level of excitatory amino acids, notably glutamate, in learning-relevant brain structures, such as the hippocampus (Venero \& Borrell, 1998).

\section{INVOLVEMENT OF BRAIN GLUCOCORTICOID RECEPTORS IN MEMORY FORMATION}

As stated in the Introduction, glucocorticoid levels are generally elevated in learning situations and enter the brain, where they bind to specific receptors in brain regions, notably limbic structures and the cerebral cortex, that are involved in learning and memory. Would the activation of central glucocorticoid receptors play a role in memory formation? Addressing this question has been 
facilitated by the development of specific antagonists for each intracellular receptor type, MR (RU28318) and GR (RU38486).

The passive avoidance learning paradigm in the one-day-old chick appears particularly suitable for studying the contribution of glucocorticoids to the mechanisms that are implicated in memory storage. In the passive avoidance task, chicks learn to avoid a bead that is coated with a distasteful substance, a learning response that chicks quickly acquire with a single trial and maintain for several days, even weeks, given the survival value of such behavior in avoiding potentially harmful non-food items. On training, chicks display a stress reaction, manifested by either distress vocalizations or backing away from the bead. In the minutes to hours after training, a molecular and cellular cascade occurs in specific brain regions, including the intermediate medial hyperstritum ventrale (IMHV) (for reviews, see Rose, 1995; Stewart \& Rusadov, 1995), an area that contains a high density of corticosteronebinding sites. Before training, the administration of selective MR or GR antagonists in the IHMV of chicks interferes with the subsequent expression of the avoidance response (Sandi \& Rose, 1994a). Further experiments revealed that the MR antagonist alters the bird's reactivity to nonspecific aspects of the training tasks, thereby influencing the acquisition of information during learning. An action through the GR, however, appeareds to be involved in the modulation of the memory consolidation mechanisms. Because of technical limitations (any intracerebral injection given immediately after training renders chicks amnestic), the effects of the antagonists could not be tested immediately after training, limiting the interpretation of the results regarding the timing of involvement, acquisition and/or consolidation of GR on information processing. The result that amnesia did not develop until $>30$ min after training supports an action of GR receptors on consolidation.

Interestingly, a similar suggestion was also proposed by Oitzl \& de Kloet (1992) to explain the action of MR and GR on spatial orientation learning in rats, using the Morris water maze (Morris et al., 1982). This learning task requires animals, helped by extra-maze cues, to find a submerged platform, an activity that requires intact hippocampal functioning. The intracerebroventricular administration of antagonists for each receptor type disturbs different aspects of spatial learning. Whereas the MR antagonist alters the search strategies that are required for the learning process, GR-receptor blockade interferes with the process of memory storage of the newly acquired spatial information (Oitzl \& de Kloet, 1992).

Each receptor type, therefore, appears to modulate a different mechanism involved in the overall process of memory formation. Thus, the optimal occupancy of MRs seems to be required for acquisition, whereas an action through GRs appears to be involved in the modulation of memory consolidation mechanisms. Recent work has been designed to question whether brain MRs and GRs might also be involved in the formation of long-term memory for traumatic experiences, and whether such involvement might be related to the intensity of the stressor. For this purpose, contextual fear conditioning, a task that is also hippocampusdependent (Kim \& Fanselow, 1992), was selected. In this task, rats develop a characteristic immobility or "freezing" response when re-exposed to the context in which they had previously experienced brief, inescapable shocks. Previous studies involving the peripheral administration of GR antagonists implicated these receptors in the consolidation of contextual fear conditioning in the juvenile rat (Pugh et al., 1997). In the adult rat, the ability of intracerebroventricularly injected $\mathrm{MR}$ and GR antagonists to influence memory formation for the contextual fear conditioning that is elicited by different shock intensities was tested (Cordero \& Sandi, 1998). We found that administration of the $\mathrm{GR}$, but not the MR, antagonist before conditioning rats with a moderate shock intensity $(0.4 \mathrm{~mA})$ attenuates long-term expression (as observed at 24 $\mathrm{hr}$ and $7 \mathrm{~d}$ after training) of contextual fear conditioning. In contrast, treatment with the antagonists before conditioning with a high shock intensity $(1 \mathrm{~mA})$ fails to influence the extent of fear conditioning, which suggests that interference with long-term memory formation by the blockade of brain GRs might be effective only for learning situations that involve a me derate stress component, but ineffective when dealing with the storage of more traumatic experiences. 


\section{CIRCULATING GLUCOCORTICOID LEVELS AND MEMORY STORAGE}

Interventive pharmacological studies support a role for a glucocorticoid action in the brain through the GR type on the neural mechanisms underlying long-term memory formation. Does any physiological evidence exist to support the involvement of glucocorticoids in the processes that mediate consolidation? Evidence has now been provided for such an involvement in the animal learning models described above. The experimental strategies that were developed to address this issue took advantage of the psychological principle by which the learning level depends on the intensity of the unconditional stimulus. Thus, the animals were trained at varying intensities of the different stimuli that were included in each learning task, and then the level of corticosterone during the post-training period and the behavioral assessment of long-term memory for the tasks were analyzed. Such studies were complemented by the evaluation of the behavioral consequence of manipulating the steroid level by injecting exogenous corticosterone.

In the passive avoidance model that we used to train chicks, the distasteful substance, methylanthranilate (MeA), which in normal testing is used in pure form $(100 \%)$ to coat the training bead (standard, strong task), was diluted to $10 \%$ in ethanol (weak training task) (Sandi \& Rose, 1994b). Whereas chicks trained in the standard version of the task retained the avoidance response for several days, those trained on the modified weak training task retained the avoidance response for less than $10 \mathrm{hr}$. The evaluation of corticosterone levels that were induced by training the chicks in both training conditions, standard versus weak, indicated that only the chicks that are trained on the strong task experience an increased release of plasma corticosterone as a consequence of training, whereas chicks that are trained on the weak task show circulating corticosterone values that are comparable to those of untrained chicks (Sandi \& Rose, 1997a). The two-fold increase in corticosterone levels displayed by the 100\% MeA-trained birds was apparent at $5 \mathrm{~min}$ post-training and returned to basal levels by $15 \mathrm{~min}$ post-training, which agrees with the rapid corticosteroid responses to stress displayed by chicks during the early post-hatching period. Accordingly, the training condition resulting in long-term memory formation also induces the enhanced release of corticosterone. In addition, when given up to $1 \mathrm{hr}$ after training chicks in the weak task, intracerebral administration of corticosterone ( $1 \mu \mathrm{g} /$ chick) into the IMHV facilitates long-term memory retention in chicks that are tested $24 \mathrm{hr}$ after training (Sandi \& Rose, 1994b), and injection of the glucocorticoidsynthesis inhibitors metyrapone and aminoglutethimide interferes with memory formation for the strong task (Loscertales et al., 1997). In the strong task, however, the same corticosterone dose produces an impairment in long-term retention for the avoidance response (Sandi \& Rose, 1997a). The results of these studies, in addition to supporting the crucial role of corticosterone release after training on the physiological mechanism enabling the transition from short-term to long-term memory, suggest a biphasic modulation of memory formation by acute corticosterone administration.

In the water-maze task, the stimulus intensity (the temperature of the water tank) was also varied. Previously, evidence was presented (Morris, 1984) indicating that water temperature is a factor that might influence the acquisition rate of this task. Indeed, rats that are trained at $19^{\circ} \mathrm{C}$ display a quicker rate of acquisition and better long-term retention than those that are trained at $25^{\circ} \mathrm{C}$ (Sandi et al., 1997a). Corticosterone levels, evaluated during the post-training period of the first training day, are significantly higher in rats in the $19^{\circ} \mathrm{C}$ group than those in the $25^{\circ} \mathrm{C}$ group. In addition, in rats that are trained at $25^{\circ} \mathrm{C}$, but not at $19^{\circ} \mathrm{C}$, performance is improved by an intraperitoneal injection of corticosterone immediately after each training session. The corticosterone dose used, 5 $\mathrm{mg} / \mathrm{kg}$, induces plasma values of the steroid that are comparable to those elicited by substantial stress (Venero et al., 1996). Therefore, the results of this study support a facilitative role for corticosterone during the post-training period on the neural mechanisms determining the strength of spatial information storage.

Further evidence for a role of corticosterone on the consolidation and expression of a learned behavior was gleaned using the contextual fear 


\section{Passive avoidance learning Chicks}

\section{Spatial orientation learning Rats}
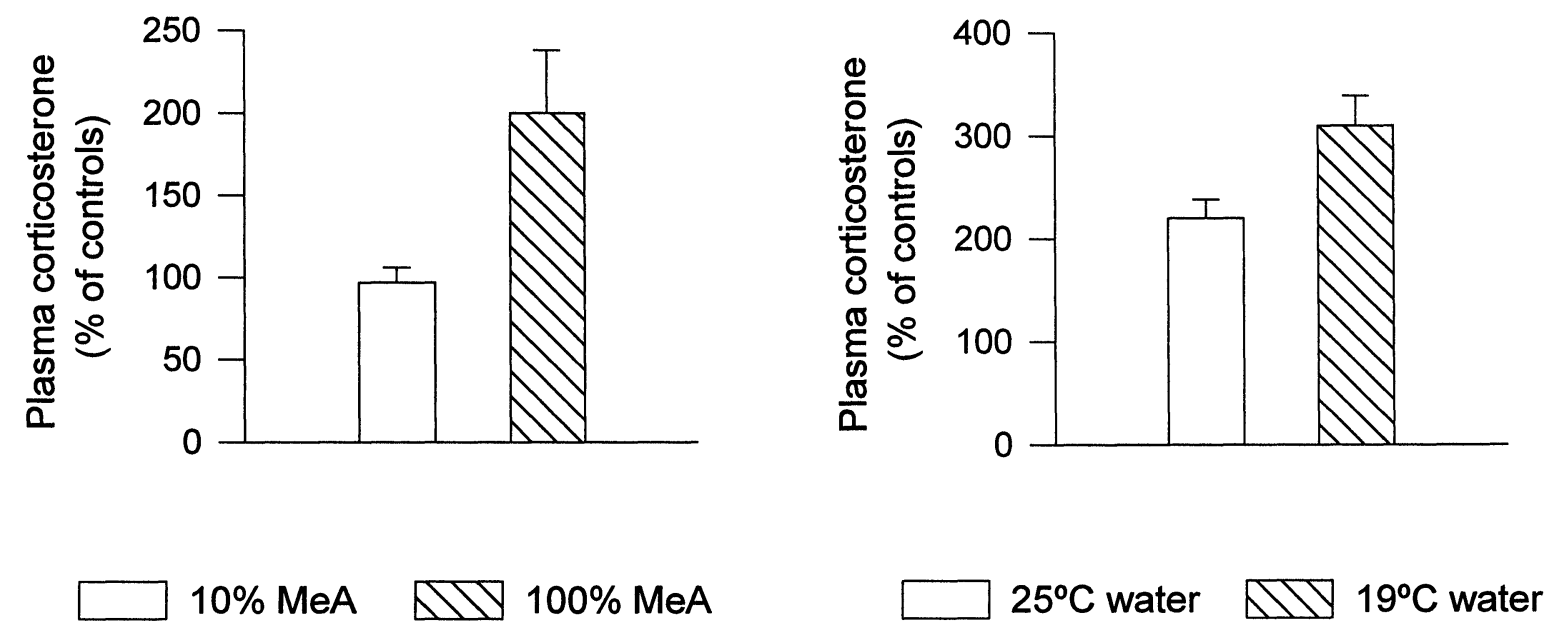

\section{Contextual fear conditioning Rats}

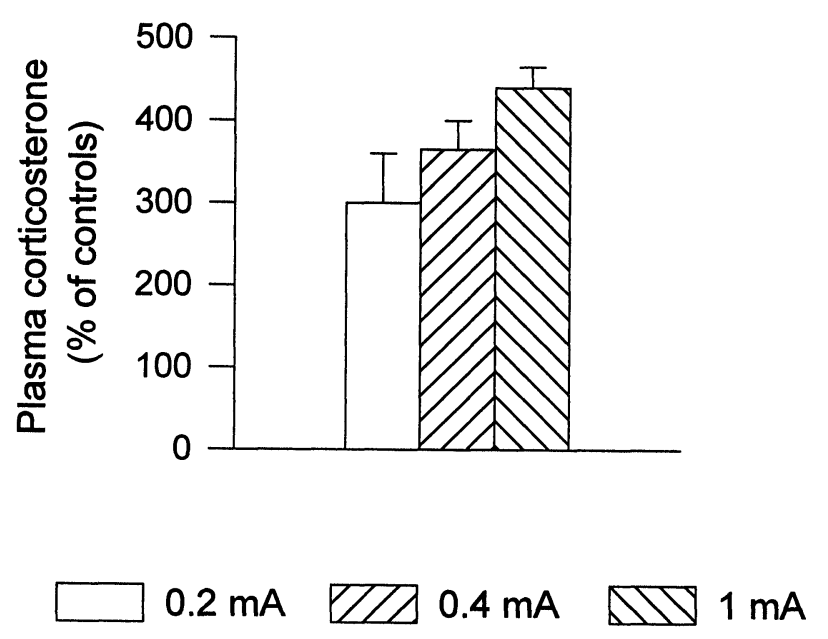

Fig. 1: The effect on post-training plasma corticosterone levels of training rats and chicks at different stimulus intensities. Left: One-day-old chicks trained with either $10 \%$ or $100 \%$ methylanthranilate $(\mathrm{MeA})$ as the aversive gustatory stimulus [adapted from Sandi \& Rose (1997a)]. Middle: Rats trained in the Morris water maze at different water temperatures were evaluated immediately after the first training day [adapted from Sandi et al. (1997)]. Right: Results obtained immediately after training rats on the contextual fear conditioning task with different shock intensities [adapted from Cordero et al. (1998)]. Data represent the mean \pm SEM, expressed as the percentage of untrained control animals. 


\section{LTP or PBP}

A)

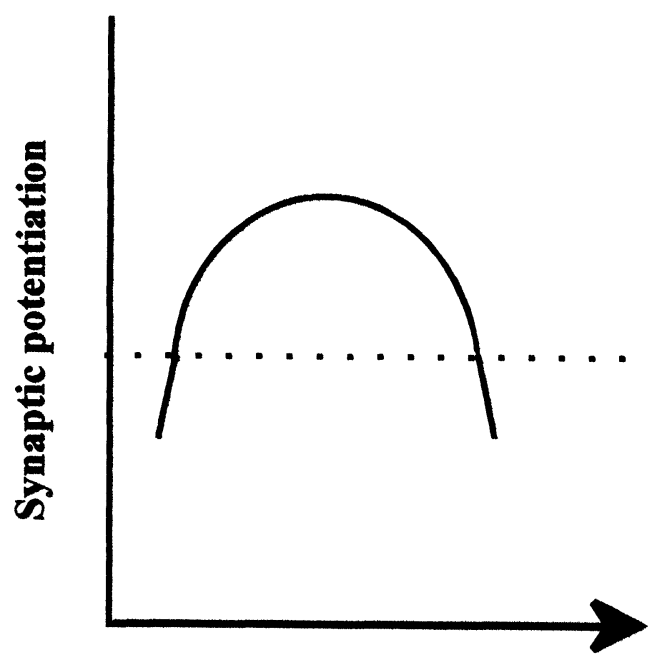

Corticosterone concentration
MEMORY CONSOLIDATION

B)

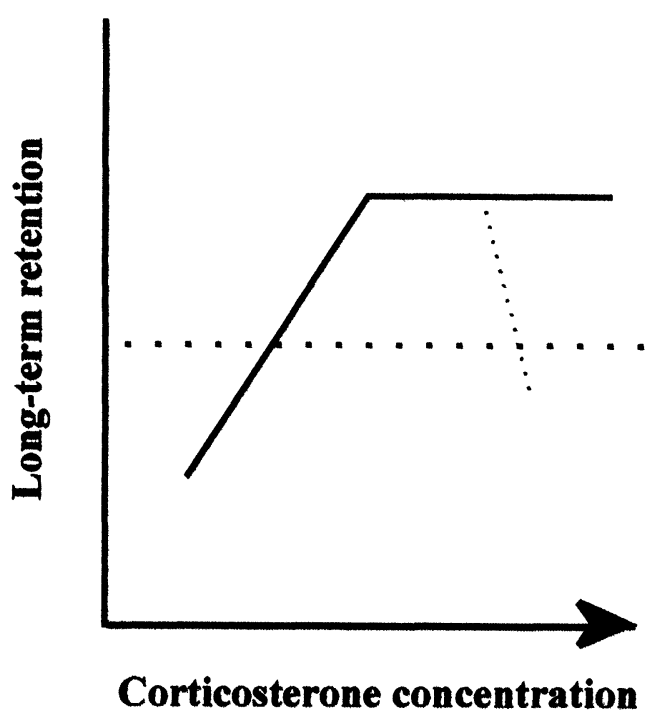

Fig. 2: Cartoon comparing the effects of circulating cortico-sterone levels on (A) the establishment of synaptic potentiation in two models of hippocampal plasticity, long-term potentiation (LTP), and primed burst potenti-ation (PBP), which reportedly follows an inverted U-shaped function; (B) long-term retention of newly acquired information, according to our hypothetical model implicating corticosterone levels in the neural mechanism that determine the strength at which information is stored into long-term memory.

conditioning model in rats. In a study reported by Cordero et al. (1998), the extent of conditioned fear and the levels of plasma corticosterone, following context exposure at training and at different posttraining times ( $24 \mathrm{hr}$ and $7 \mathrm{~d}$ ), were shown to be dependent upon the intensity of the unconditional stimulus (footshock; 0.2, 0.4, and $1 \mathrm{~mA}$ ). In each experimental session, a positive correlation was found between the magnitude of corticosterone levels and the fear-related behavioral inhibition exhibited in the context. Interestingly, freezing values at 24-hr post-training appear to be related to the corticosterone levels during the post-training period. In addition, a peripheral corticosterone injection $(5 \mathrm{mg} / \mathrm{kg})$, given to rats immediately after training at the mild shock intensity $(0.2 \mathrm{~mA})$, enhances the long-term expression of contextual fear conditioning. Therefore, further evidence proposing a concentration-dependent facilitative role of corticosterone during the post-training period in the storage of the fear response has been presented, further implicating this hormone in the long-term expression of this particular type of behavioral inhibition.

Together, the results of these studies support our view that corticosterone acts on the selection processes that occur during consolidation in determining the strength at which newly acquired information is stored as long-term memory. Training procedures that use the different stimulus intensities in the different experimental models described here share most training factors in common, including the training context, the visual characteristics of the training environment, the type 
of response that is elicited or required to be displayed by the training situation, and so on. In all cases, however, the different stimulus intensities determine both differential corticosterone responses (see Fig. 1) and different degrees of long-term retention of the learned response.

In general, the studies performed in rats that are discussed here suggest a positive relation between post-training corticosterone levels and the strength at which information is established as long-term storage, up to a ceiling limit. This view is in contrast with the corticosterone-induced, dose-dependent inverted U-shaped effects on hippocampal longterm potentiation (LTP) (Pavlides et al., 1995; Kerr et al., 1994) and primed burst potentiation (PBP) (Bennet et al., 1991; Diamond et al., 1994), two forms of synaptic plasticity that may be related to the mechanisms of memory formation. Important differences, however, may account for such a relation between corticosterone levels and the modulation of either the intensity of the memory formed or the expression of LTP or PBP.

Our argument for the role of corticosterone in memory storage focuses exclusively on the stress that is induced by a training situation, which will consequently result in enhanced steroid levels during the post-training period, and during which we propose it will have an influence on memory storage (see Fig. 2). On the other hand, LTP or PBP studies always manipulate the steroid levels before the induction of the potentiated forms of synaptic plasticity, a situation that might resemble exposure to the learning situation under circumstances of previously induced stress or glucocorticoid elevation. The influence of stress or steroid elevation on learning is a topic different from that discussed in this article, which strictly explores the contribution of steroid increases that are induced by the training situation on the mechanisms of memory formation.

Nevertheless, we should also mention that studies on passive avoidance learning in experiments in which corticosterone administration after strong training impaired memory storage (Sandi \& Rose, 1997a), would also account for a dose-dependent inverted U-shaped effect of post-training corticosterone on consolidation. The possibility, however, that this effect is pharmacological rather than physiological cannot be disregarded, given that the circulating corticosterone levels in the chicks had already reached a maximum as a consequence of strong passive avoidance training.

\section{EFFECTS OF CHRONIC GLUCOCORTICOID ELEVATION ON LEARNING AND MEMORY}

I will briefly mention the implication of chronic glucocorticoid exposure on memory, for which certain recent evidence indicates that sustained elevation of glucocorticoids result in cognitive deficits (McEwen \& Sapolsky, 1995; Bodnoff et al., 1995; Lupien et al., 1998). Morphological studies have shown that prolonged exposure to stress or to excess glucocorticoids results in time-dependent neuronal damage, ranging from an initial and reversible atrophy of dendritic processes (Wooley et al, 1990; Watanabe et al., 1992; Magariños et al., 1995 ) to the irreversible loss (Landfield, 1987; Sapolsky et al., 1985) of hippocampal pyramidal cells. This stress- or glucocorticoid-induced structural damage appears to coincide with learning and memory deficits.

No data are available concerning the effects of chronic stress on memory in the chick. The available evidence does indicate that chronic corticosterone treatments impair spatial-orientation learning in rats in different types of mazes (Luine et al., 1993; Conrad et al., 1997). In the water maze, the efficacy of $3 \mathrm{wk}$ of exposure to elevated corticosterone levels in affecting the rate of learning was dependent upon the physiological impact produced by the steroid treatment (Sandi et al., 1997b; Loscertales et al., 1998). Rats, aged $6 \mathrm{wk}$ at the beginning of the treatment and manifesting a marked reduction in body-weight gain (around 50\%), were slower during navigation learning in the tank and swam greater distances to find the platform than did the control animals (Sandi et al., 1997b). When the steroid impact on body weight was lower (around $25 \%$ to $30 \%$ ), however, either in 6-wk-old or in 12 wk-old rats, performance during learning was not affected, although such rats showed a deficit when they had to learn again to find the submerged platform placed in a different location (Loscertales et al., 1998). 
In the contextual fear conditioning paradigm, no study has yet explored the implications of chronic corticosterone treatment. Using a restrain stress paradigm, however, which compromises hippocampal neurons in manner similar to that of chronic corticosterone (Watanabe et al., 1992), Conrad et al. (1997) found a potentiation of conditioned freezing, a result that is puzzling, given the dependence of this learning task on hippocampal functioning.

The question remains, therefore, of (i) what might be the mechanisms of action by which glucocorticoids modulate the strength of consolidation, and (ii) whether such mechanisms might explain the reversal of glucocorticoid actions from facilitating to damaging for neural function and cognition. The following section deals with studies addressing the former question. The findings will also be discussed as to their possible implications for understanding the latter query.

\section{MECHANISMS INVOLVED IN GLUCOCORTICOID ACTIONS ON MEMORY}

Among the different cellular and molecular mechanisms that have been proposed to mediate the changes in synaptic connectivity that are involved in long-term memory formation, we will focus on two main events to explore the possible influences of glucocorticoids: (i) glutamatergic transmission and (ii) cell adhesion molecules.

\section{Glutamatergic transmission}

Among the early synaptic transients implicated in learning and memory, glutamatergic transmission proved to be critical in a wide variety of learning models (Izquierdo \& Medina, 1995; Maren \& Baudry, 1995). Evidence that glucocorticoids can increase glutamate concentrations in the hippocampus, as well as in other brain regions, including the striatum and the frontal cortex, has been found in mammals (Lowy et al., 1993; Moghaddam et al.,1994; Abraham et al., 1996; Venero \& Borrell, 1998). In this way, glutamatergic activation might be a mechanism by which corticosterone influences memory storage. This possibility was evaluated in the passive avoidance learning task in the chick because this learning model is one in which memory has been shown to require the activation of the glutamate receptor types $\alpha$-amino-3-hydroxy-5methyl-4-isoazolepropionic acid (AMPA) and N-methyl-D-aspartate (NMDA) (Stewart \& Rusakov, 1995; Richard et al., 1994). Using the corticosterone-facilitative model of the weak training version of this task (see above), long-term retention was evaluated in chicks injected with either NMDA or AMPA receptor antagonists (Venero \& Sandi, 1997). When administered before training, both antagonists prevented the facilitating effect of corticosterone, but when injected before administration of the steroid in the post-training period, the antagonists failed to interfere with the steroid effect. The relatively early effectiveness of the antagonists suggests that the outcome was related not to corticosterone-induced actions but rather to training-triggered mechanisms. Nevertheless, pre-training administration of the antagonists might influence the steroid effects through the delayed expression of their actions. In addition, the AMPA receptor antagonist, when injected $5.5 \mathrm{hr}$ after training, was also found to be effective in impairing the long-term memorypotentiating effect of corti-costerone. This finding agrees with the involvement of this receptor type in memory formation for the standard passive avoidance learning at this late time point (Steele \& Stewart, 1995), and implies corticosterone actions on the late-phase molecular events that are implicated in long-term memory formation.

\section{Cell adhesion molecules}

Among the main mechanisms mediating cellular responses to glucocorticoids are receptor-mediated changes in gene expression (Burnstein \& Cidlowsky, 1989; Joëls \& de Kloet, 1994). Longterm memory formation depends on protein synthesis mechanisms in a wide number of animal models (David \& Squire, 1984); hence one mechanism by which glucocorticoids influence consolidation might be the genomic modulation of the synthesis of certain proteins that are implicated in the synaptic restructuring and stabilization subserving memory storage. An increasing number 
of studies emphasize a role for certain cell-surface glycoproteins, the cell adhesion molecules (CAMs) that display recognition and adhesion properties, particularly the neural cell adhesion molecule (NCAM) and L1 (Scholey et al., 1993; Cremer et al., 1994; Lüthi et al., 1994; Fox et al., 1995; Muller et al., 1996). Interestingly, the involvement of CAMs in the neural mechanisms of memory appears to occur several hours after the training experience (from 6-24 hr afterwards, depending on the animal and the learning task.

The hypothesis that corticosterone facilitation of long-term memory formation might be dependent upon a late-phase modulation of CAMs was first investigated in the chick passive avoidance learning task (Sandi et al., 1995). The functional state of CAMs is modulated through post-translational glycosylation; glycoprotein fucosylation is involved in the transition mechanisms from short-term to long-term memory (Rose, 1995). This mechanism was also implicated in the facilitative effect of corticosterone on consolidation. Thus, intracerebral corticosterone injection enhances protein fucosylation in the IMHV of untrained chicks at 5.5 to 8.5 $\mathrm{hr}$ post injection, a result that is analogous to that elicited by training chicks on the strong passive avoidance task (Sandi et al., 1995). Further studies involving pharmacological and biochemical experiments, including the fucosylation inhibitor 2-deoxygalactose, the protein synthesis inhibitor anisomycin, and radiolabeled fucose, indicated that the late phase of glycoprotein synthesis involved in the memory-facilitating effect of corticosterone occurs on newly synthesized proteins (Sandi \& Rose, 1997b). NCAM, which shows enhanced fucosylation as a consequence of training in the standard task (Scholey et al., 1993), is also implicated in the steroid effect because antibodies against this molecule (administered $5.5 \mathrm{hr}$ posttraining) prevent the memory-facilitating effect that is induced by corticosterone in the weak task (Sandi et al., 1995).

In rats, glucocorticoids have also been found to influence the expression and modulation of CAMs. Thus, an intraperitoneal corticosterone injection of a dose $(5 \mathrm{mg} / \mathrm{kg})$ that facilitates memory for weak versions of the water maze (Sandi et al., 1997a) and contextual fear conditioning ( Cordero \& Sandi,
1998) tasks, results in decreased glycoprotein synthesis in the hippocampus and the striatum at $3 \mathrm{hr}$ post-injection (Venero et al., 1996). The same dose was also shown to induce increased levels of NCAM expression in the frontal, including the prefrontal cortex at $8 \mathrm{hr}$ and $24 \mathrm{hr}$ post-injection. (Sandi \& Loscertales, submitted). Given the key role of the brain areas showing corticosteroneinduced modulation of CAMs on the mechanism of learning and memory, these findings suggest that these molecules are potential mediators of glucocorticoid actions that determine the strength of memory consolidation. In fact, NCAM levels at the hippocampus appeared to be increased after training on the contextual fear conditioning paradigm (Sandi et al., 1998).

The possibility that the CAMs were modulated by chronic glucocorticoid treatments that are known to produce morphological (Wooley et al., 1990) and cognitive (Luine et al., 1993; Sandi et al., 1997b; Loscertales et al., 1998) deficits has also been addressed. Exposure of rats to a 21-day corticosterone treatment results in reduced glycoprotein fucosylation in the hypothalamus (Venero et al., 1996), as well as reduced NCAM expression in this brain region and in the frontal/ prefrontal cortex (Sandi \& Loscertales, submitted). It is. interesting to note that NCAM expression in the frontal cortex shows a reversed regulation by corticosterone treatments that results in opposite cognitive actions (see above), which might have implications in understanding the cellular and molecular mechanisms by which glucocorticoid actions at the brain turn from facilitating to deleterious as the period of exposure increases. Work is currently in progress to elucidate further the relation between glucocorticoids, CAMs, and cognition.

\section{CONCLUSIONS}

Although individuals do not require the activation of stress-related systems to learn a variety of new information, most current animal models do imply a stress response. Experimental evidence from different animal and learning tasks support the hypothesis that glucocorticoid levels during the 
post-training period, by acting at specific glucocorticoid receptor types in the brain, modulate memory formation. In our view, glucocorticoids would act on the neural mechanisms underlying the selection processes that occur during consolidation in determining the strength at which new information is stored as long-term memory. Current work suggests CAMs as possible targets to mediate glucocorticoid actions on memory storage.

\section{ACKNOWLEDGMENTS}

Part of this work was supported by a DGES grant (PM96 0015) from the Ministry of Education and Culture, Spain, and the European Training Programme on the Neural Mechanisms of Learning and Memory (ESF). The author wishes to thank the contributions to parts of the work cited in this manuscript from $M$. Isabel Cordero, María Loscertales, J. Joaquín Merino, and César Venero, as well as thanking Dr. Jonathan Daisley for helpful comments on a previous version of this paper.

\section{REFERENCES}

Abraham I, Juhsz G, Kekeksi KA, Kovacs KJ. Effect of intrahippocampal dexamethasone on the levels of amino acid transmitters and neural excitability. Brain Res 1966; 733: 56-63.

Baulieu EE. Steroid hormone antagonists at the receptor level: A role for heat shock protein M.W. 90,000 (hsp 90). J Cell Biochem 1987; 35: 161-174.

Bennet MC, Diamond DM, Fleshner M, Rose GM. Serum corticosterone level predicts the magnitude of hippocampal primed burst potentiation and depression in urethane-anesthetized rats. Psychobiology 1991; 19: 301-307.

Bodnoff SR, Humphreys AG, Lehman JC, Diamond DM, Rose GM, Meaney MJ. Enduring effects of chronic corticosterone treatment on spatial learning, synaptic plasticity, and hippocampal neuropathology in young and mid-aged rats. J Neurosci 1995; 15: 61-69.

Burnstein KL, Cidlowski JA. Regulation of gene expression by glucocorticoids. Ann Rev Physiol 1989; 51: 683-699.

Conrad CD, Galea LAM, Kuroda Y, McEwen BS. Chronic stress impairs rat spatial memory on the $Y$ maze, and this effect is blocked by tianeptine pretreatment. Behav Neurosci 1996; 6: 1321-1334.
Cordero MI, Merino JJ, Sandi C. Correlational relationship between shock intensity and corticosterone secretion on the establishment and subsequent expression of contextual fear conditioning. Behav Neurosci 1998; 112 (in press).

Cordero MI, Sandi C. A role for brain glucocorticoid receptors in contextual fear conditioning: dependence upon training intensity. Brain Res 1998; 786: 11-17.

Cremer H, Lange R, Christo HA, Plomann M, Vopper G, Roes J, et al. Inactivation of the N-CAM gene in mice results in size reduction of the olfactory bulb and deficits in spatial learning. Nature 1994; 367: 455-459.

Davis HP, Squire LR. Protein synthesis and memory: a review. Psychol Bull 1984; 96: 518-559.

Diamond DM, Fleshner M, Rose GM. Psychological stress repeatedly blocks hippocampal primed burst potentiation in behaving rats. Behav Brain Res 1994; 62: 1-9.

Dokas LA, Schlatter LK, Barr CS. Corticosteroid-induced proteins in brain. Ann NY Acad Sci 1994; 746: 157163.

Fox GB, O'Connell AW, Murphy KJ, Regan CM. Memory consolidation induces a transient and timedependent increase in the frequency of neural cell adhesion molecule polysialyated cells in the adult rat hippocampus. J Neurochem 1995; 65: 2796-2799.

Izquierdo I, Medina JH. Correlation between the pharmacology of long-term potentiation and the pharmacology of memory. Neurobiol Learn Mem 1995; 63: 19-32.

Joëls M, de Kloet ER. Mineralocorticoid and glucocorticoid receptors in the brain. Implications of ion permeability and transmitter systems. Prog Neurobiol 1994; 43: 1-36.

Kerr DS, Huggett AM, Abraham WC. Modulation of hippocampal long-term potentiation and long-term depression by corticosteroid receptor activation. Psychobiology 1994; 22: 123-133.

Kim JJ, Fanselow M. Modality-specific retrograde amnesia of fear. Science 1992; 256: 675-676.

Landfield PW. Modulation of brain aging correlates by long-term alterations of adrenal steroids and neurally active peptides. Prog Brain Res 1987; 72: 279-300.

Loscertales M, Guaza C, Sandi C. Effects of chronic corticosterone exposure on water maze performance and NCAM expression. Forum Meeting of European Neuroscience. Eur J Neurosci 1998 (Suppl); 10: 263.

Loscertales M, Rose SPR, Sandi C. The corticosterone synthesis inhibitors metyrapone and aminoglutethimide block long-term memory for a passive avoidance task in day-old chicks. Brain Res 1997; 769: 357-361.

Lowy MT, Wittenberg L, Novotney S. Adrenalectomy attenuates stress-induced elevations in extracellular glutamate concentrations in the hippocampus. J Neurochem 1993; 61: 1957-1960.

Luine VN, Spencer RL, McEwen BS. Effect of chronic corticosterone ingestion on spatial memory performance and hippocampal serotonergic function. 
Brain Res 1993; 616: 55-70.

Lupien SJ. De Leon M, de Santi S, Convit A, Tarshish C, Nair NPV, et al. Cortisol levels during human aging predict hippocampal atrophy and memory deficits. Nature Neurosci 1998; 1: 67-73.

Lüthi A, Laurent J-P, Figurov A, Muller D, Schachner M. Hippocampal long-term potentiation and neural cell adhesion molecules L1 and NCAM. Nature 1994; 372: 777-779.

Magariños AM, McEwen BS. Stress-induced atrophy of apical dendrites of hippocampal CA3c neurons: Involvement of glucocorticoid secretion and excitatory amino acid receptors. Neuroscience 1995; 69: 89-98.

Maren S, Baudry M. Properties and mechanisms of longterm synaptic plasticity in the mammalian brain: relationships to learning and memory. Neurobiol Learn Mem 1995; 63: 1-18.

McEwen BS, Sapolsky RM. Stress and cognitive function. Curr Op Neurobiol 1885; 5: 205-216.

Moghaddam B, Bolinao ML, Stein-Behrens B, Sapolsky R. Glucocorticoids mediate the stress-induced extracellular accumulation of glutamate. Brain Res 1994; 655: 251-254.

Morris RG, Garrud P, Rawlins JNP, O'Keefe J. Place navigation impaired in rats with hippocampal lesions. Nature 1982; 297: 681-683.

Muller D, Wang C, Skibo G, Toni N, Cremer H, Calaora $\mathrm{V}$, et al. NCAM is required for activity-induced synaptic plasticity. Neuron 1996; 17: 413-422.

Oitzl M, de Kloet ER. Selective corticosteroid antagonists modulate specific aspects of spatial orientation learning. Behav Neurosci 1992; 106: 62-71.

Orchinik M, Murray TF, Moore FL. A corticosteriod receptor in neuronal membranes. Science 1991; 252: 1848-1851.

Pavlides C, Watanbe Y, Magariños AM, McEwen BS. Opposing roles of type I and type II adrenal steroid receptors in hippocampal long-term potentiation. Neuroscience 1995; 68: 387-394.

Pugh CR, Fleshner P, Rudy JW. Type II glucocorticoid receptor antagonists impair contextual but not auditory-cue fear conditioning in juvenile rats. Neurobiol Learn Mem 1997; 67: 75-79.

Puia G, Santi MR, Vicini S, Pritchett DB, Purdy RH, Paul $\mathrm{SM}$, et al. Neurosteriods act on recombinant human $\mathrm{GAGA}_{\mathrm{A}}$ receptors. Neuron 1990; 4: 759-765.

Rickard NS, Poot AC, Gibbs ME, Ng KT. Both nonNMDA and NMDA glutamate receptors are necessary for memory consolidation in the day-old chick. Behav Neurol Biol 1994; 62: 33-40.

Rose SPR. Glycoproteins and memory formation. Behav Brain Res 1995; 66: 206-213.

Sandi C, Loscertales M, Merino JJ, Cordero MI, Guaza C. Time-dependent biphasic actions of glucocorticoids on spatial memory and NCAM expression in the frontal cortex of rats. Neurosci Abstr 1997b; 23: 2121.
Sandi C, Merino JJ, Cordero MI. Involvement of central glucocorticoid receptors and NCAM in memory consolidation for contextual fear conditioning. Forum Meeting of European Neuroscience. Eur J Neurosci 1998 (Suppl); 10: 115.

Sandi C, Rose SPR. Mileusnic R, Lancashire C. Corticosterone facilitates long-term memory formation via enhanced glycoprotein synthesis. Neuroscience 1995; 69: 1087-1093.

Sandi C, Rose SPR. Corticosteroid receptor antagonists are amnestic for passive avoidance learning in day-old chicks. Eur J Neurosci 1994a; 6: 1292-1297.

Sandi C, Rose SPR. Corticosterone enhances long-term retention in one-day-old chicks trained in a weak passive avoidance learning paradigm. Brain Res 1994b; 647: 106-112.

Sandi C, Rose SPR. Protein synthesis- and fucosylationdependent mechanism in corticosterone facilitation of long-term memory in the chick. Behav Neurosci 1997b; 111: 1098-1104.

Sandi C, Rose SPR. Training-dependent biphasic effects of corticosterone in memory formation for a passive avoidance task in chicks. Psychopharmacology 1997a; 133: 152-160.

Sandi C, Venero C, Guaza C. Nitric oxide synthesis inhibitors prevent rapid behavioral effects of corticosterone. Neuroendocrinology 1996b; 63: 446-453.

Sandi C, Venero C, Guaza C. Novelty-related rapid locomotor effects of corticosterone in rats. Eur J Neurosci 1996a; 8: 794-800.

Sapolsky RM, Krey L, McEwen BS. Prolonged glucocorticoid exposure reduces hippocampal neuron number: implications for aging. J Neurosci 1985; 5: 1221-227.

Scholey AB, Rose SPR, Zamani MR, Bock E, Schachner M. A role for the neural cell adhesion molecule in a late, consolidating phase of glycoprotein synthesis six hours following passive avoidance training of the young chick. Neuroscience 1993; 55: 499-509.

Schumacher M. Rapid membrane effects of steroid hormones: an emerging concept in neuroendocrinology. Trends Neurosci 1990; 13: 359-362.

Steele RF, Stewart MG. Involvement of AMPA receptors in maintenance of memory for a passive avoidance task in day-old chicks (Gallus domesticus). Eur J Neurosci 1995; 7: 1297-1304.

Stewart MG, Rusakov D. Short- and long-term correlates of memory formation in the chick following one-trial passive avoidance training. Behav Neurosci 1995; 66: 21-28.

Venero C, Borrell J. Acute corticosterone administration induces a rapid increase in hippocampal glutamate levels. Forum Meeting of European Neuroscience. Eur J Neurosci 1998; (Supp) 10: 295

Venero C, Guaza C, Sandi C. Regional and temporal modulation of brain glycoprotein synthesis by corticosterone. NeuroReport 1996; 7: 2819-2822. 
Venero C, Sandi C. Effects of NMDA and AMPA receptor antagonists on corticosterone facilitation of long-term memory in the chick. Eur J Neurosci 1997; 9: 19231928.

Wantanabe Y, Gould E, McEwen BS. Stress induces atrophy of apical dendrites of hippocampal CA3 pyramidal neurons. Brain Res 1992; 588: 341-345.

Woolley CS, Gould E, McEwen BS. Exposure to excess glucocorticoids alters dendritic morphology of adult hippocampal pyramidal neurons. Brain Res 1990; 531: 225-231. 

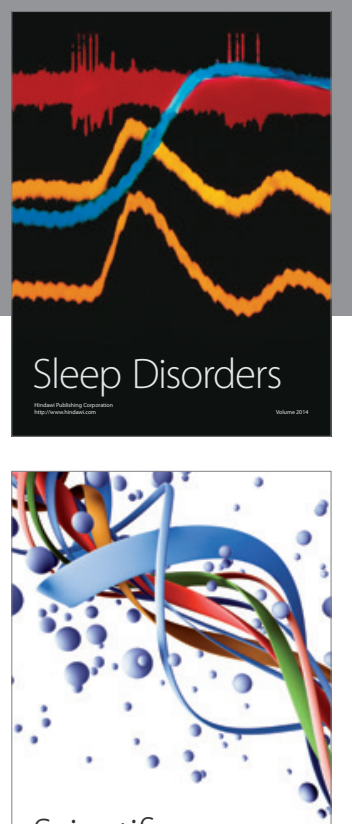

Scientifica
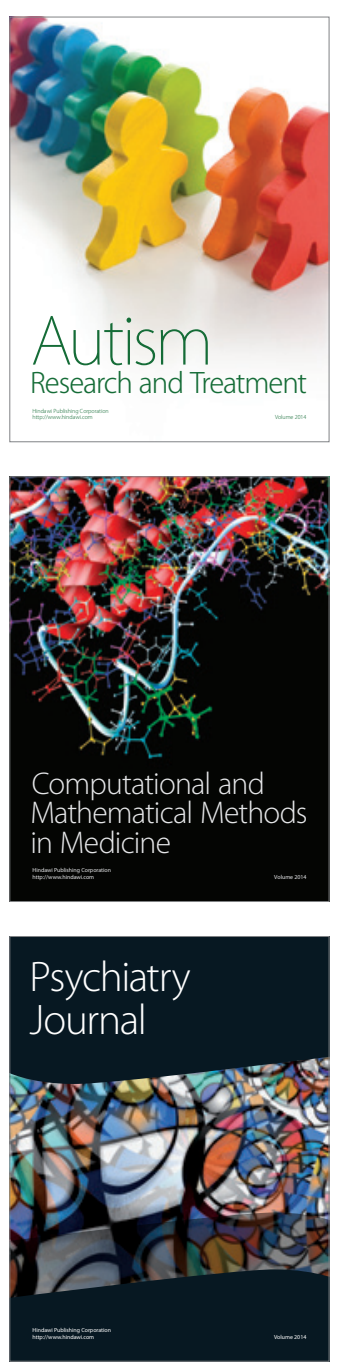
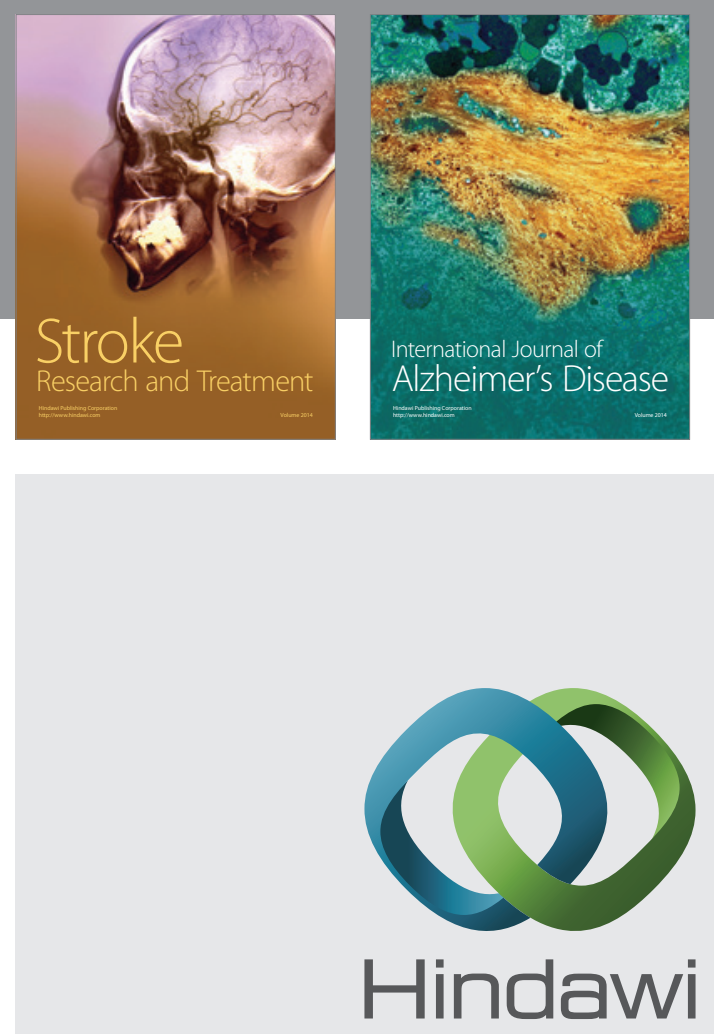

Submit your manuscripts at

http://www.hindawi.com
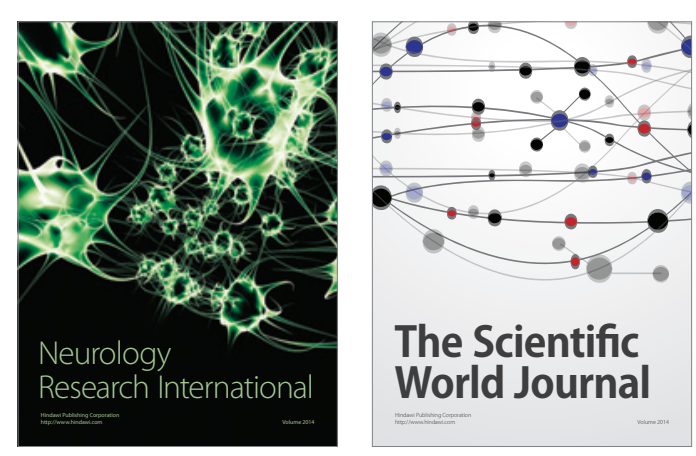

The Scientific World Journal

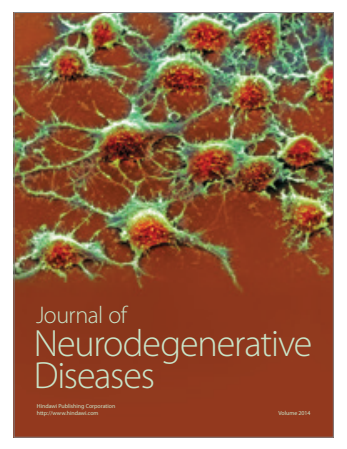

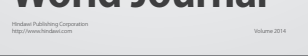

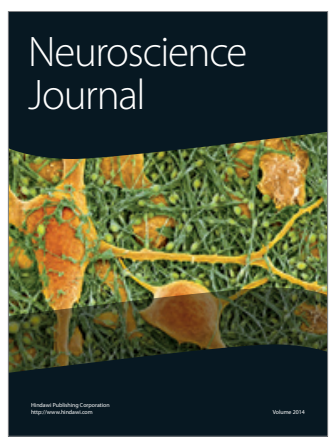

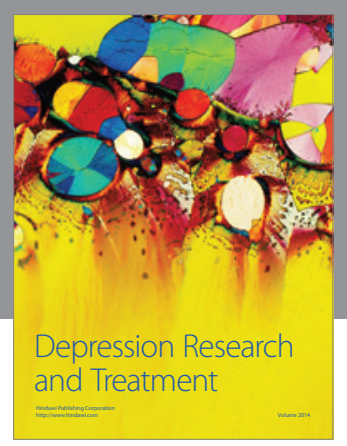
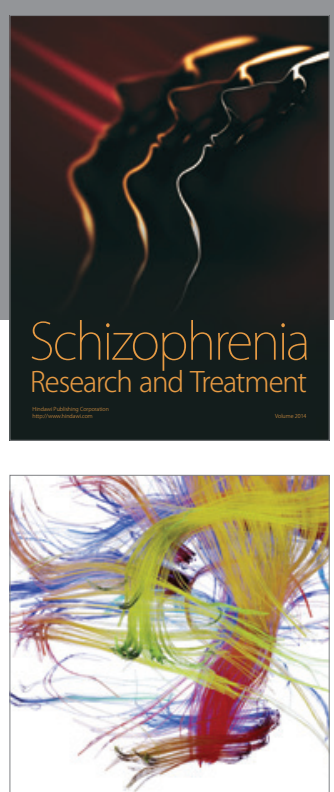

Brain Science

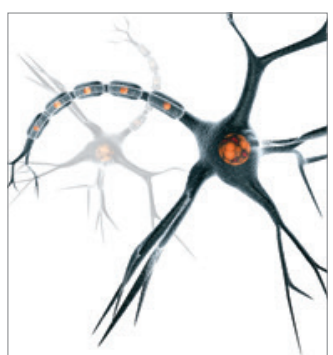

Neural Plasticity
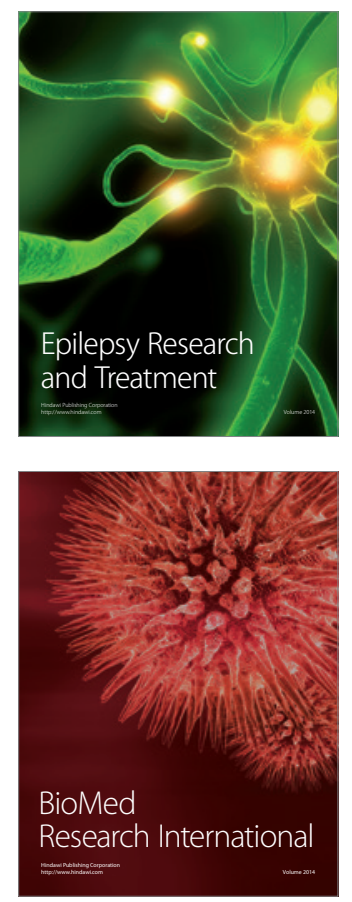

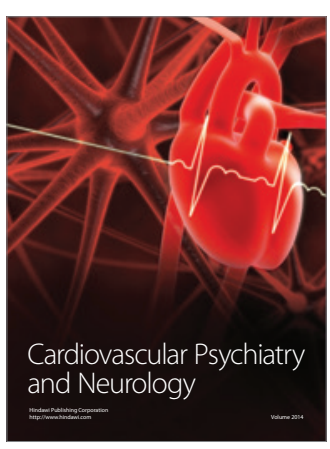

Parkinson's

Disease
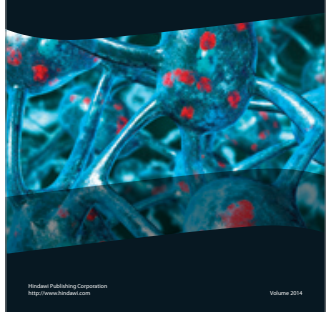